\title{
Mídia e o movimento paralímpico no Brasil: relações sob o ponto de vista de dirigentes do Comitê Paralímpico Brasileiro
}

CDD. 20.ed. 796.019

796.5

\section{Resumo}

0 objetivo deste trabalho foi investigar formas de relação entre a mídia e a divulgação e comercialização do movimento paralimpico brasileiro. A metodologia de pesquisa baseou-se: em entrevistas semiestruturadas com gestores do Comitê Paralímpico Brasileiro, relativas a processos de administração do movimento paralímpico e formas de relação deste com meios de comunicação; Análise de dados através do método "Discurso do Sujeito Coletivo"; Discussão fundamentada em categorias da obra de Pierre Bourdieu. Resultados: a exploração do movimento paralímpico por parte da mídia brasileira é algo que pode ser melhorado; 0 esporte paralímpico ainda não possui um capital simbólico que o legitime comercialmente, embora tenha evoluído neste aspecto; Para alcançar maior relevância comercial, pode ser interessante que o movimento paralímpico continue seu processo de busca por aumento da profissionalização e se adeque a direções propostas pela mídia. Talvez com isso, venha a melhorar a exposição de sua vertente esportiva de alto rendimento, destacando sua capacidade de criar ídolos, produzir emoções prazerosas e atrair interesse de espectadores.

Palavras-chave: Esporte; Paralímpico; Mídia; Atividade motora adaptada; Pierre Bourdieu.

\section{Introdução}

Durante o século XXI, o movimento paralímpico vem sofrendo algumas alterações estruturais relativas principalmente ao aumento de financiamento a atletas e equipes e a estratégias de "marketing" que visam maior divulgação desta forma de esporte como um produto de mercado ${ }^{1}$. Tais perspectivas, pouco vislumbradas até o final da década de 90 , têm produzido certa transformação social em relação à participação e reconhecimento de pessoas com deficiência em posições de destaque na sociedade, seja pelo aumento do número de espaços que oferecem atividades esportivas adaptadas, seja pela ascensão social promovida pelo esporte de alto rendimento ${ }^{2}$.

Nota-se o crescimento da comercialização e aumento do financiamento destinado ao esporte paralímpico, o que acaba sendo uma possibilidade de ascensão e reconhecimento social para o sujeito com deficiência ${ }^{3}$. Indícios deste fenômeno podem ser verificados em dados sobre receitas destinadas à participação do Brasil nos Jogos Paralímpicos (JP). Enquanto na década de 80 o país já teve dificuldade para enviar delegações aos Jogos ${ }^{4}$, o Comitê Paralímpico Brasileiro recebeu como patrocínio em 2008 cerca de $\mathrm{R} \$ 15$ milhões das Loterias Caixa e R 2 milhôes da Cosipa 5 .

Deste modo, o esporte paralímpico passa a exprimir mais do que apenas uma oportunidade de inclusão social para pessoas com deficiência. Atualmente coloca-se na sociedade como um dos produtos do mercado esportivo. Essa mudança de perspectiva tem aumentado o poder econômico das entidades organizadoras deste tipo de esporte ${ }^{6}$.

O capital econômico tem grande importância em qualquer prática esportiva de alto rendimento, sendo ele um fator que possibilita melhoria dos processos de preparação e competição. Para sua geração e captação é preciso que o esporte seja visto como
*Escola de Educação Física e Esporte de Ribeirão Preto, Universidade de São Paulo. ${ }^{* *}$ Faculdade de Educação Física, Universidade Estadual de Campinas.

***Escola de Artes, Ciências e Humanidades,

Universidade de São

Paulo. 
um produto capaz de gerar receita e atrair empresas investidoras ${ }^{7}$. O interesse comercial no esporte se pauta por sua proximidade com espectadores que se tornam consumidores e o desejo de empresas se aproximarem dessas pessoas para vender seus produ$\operatorname{tos}^{6}$. A divulgação do esporte paralímpico se coloca como uma necessidade neste universo e forma de expandir ideais inclusivos, esportivos e comerciais.

Justifica-se assim, a importância da mídia para o esporte, como meio de proliferação de valores e símbolos específicos, além de aumento de seu potencial mercadológico. Existe uma interdependência entre mídia, exposição e acúmulo de verbas no esporte-espetáculo, sob a qual os meios de comunicação precisam do esporte como conteúdo a ser comercializado e o esporte precisa ser divulgado de modo a gerar ganhos financeiros $^{7}$. Neste universo, tanto a mídia se adapta ao esporte, quanto as entidades esportivas moldam-se para que sejam comercializáveis pelos meios de comunicação ${ }^{8}$.

Segundo Bourdieu ${ }^{9}$, a notícia tem de ser vendida ao público e por isso os meios de comunicação acabam priorizando assuntos que atraiam mais consumidores. Logo, o esporte para pessoas com deficiência tem de se transformar em algo mais interessante e atraente do ponto de vista midiático e comercial, o que exige, por parte das entidades organizadoras do movimento paralímpico, formas de atuação voltadas à profissionalização.

No Brasil, a Lei Federal no 9615, conhecida como Lei Pelé ${ }^{10}$, caracteriza a prática esportiva profissional como uma ação baseada na "... remuneração pactuada em contrato formal de trabalho entre o atleta e a entidade de prática desportiva" e a prática não-profissional “... pela liberdade de prática e pela inexistência de contrato de trabalho, sendo permitido o recebimento de incentivos materiais e de patrocínio". A maior parte dos atletas paralímpicos brasileiros que recebem algum tipo de financiamento o faz por meio de bolsas governamentais (como o Bolsa-atleta, por exemplo) ou patrocínios ${ }^{11}$, caracterizando-se como não-profissionais perante a lei, embora muitos garantam seu sustento diário a partir de tais rendimentos.

Considerando esta realidade e a definição de profissionalismo esportivo proposta por $\mathrm{HowE}^{6}$ - situação em que atletas recebem recompensas financeiras para competirem e se dedicarem à melhora de seu desempenho atlético -, este estudo, quando se refere à prática esportiva profissional, o faz com a intenção de abarcar as inúmeras formas de financiamento esportivo a atletas e demais agentes sociais deste espaço. Deste modo, passa a reconhecer que muitos deles, embora não possuam contrato formal de trabalho, ainda assim, assumam um comportamento próprio do profissionalismo e tenham no esporte o meio para seu sustento e possibilidade de eventual carreira profissional legalmente constituída.

Pode-se então questionar: Como é a relação da mídia com o movimento paralímpico no Brasil? É a partir desta pergunta que se coloca este trabalho. Com base em coleta de discursos de dirigentes do Comitê Paralímpico Brasileiro (CPB), buscou-se mapear e pontuar processos e formas de relação entre a mídia e o esporte paralímpico, propondo uma reflexão, com base na obra de Pierre Bourdieu, sobre os avanços e dificuldades para a divulgação desta forma de manifestação esportiva no século XXI. Tal opção metodológica se sustenta na consideração de que o esporte, além de espaço de atividade física e desenvolvimento moral, se afirma como nicho de disputas políticas e sociais ${ }^{12}$.

Os benefícios oriundos das conclusōes desta pesquisa justificam-se na apresentação de características sociais ainda não documentadas e atuais do movimento paralímpico brasileiro, além da exploração de formas de relação de poder presentes na sociedade e que exercem interferência sobre esta forma de esporte. Além disso, cria a oportunidade de reflexão sobre as maneiras de interação e gerência do objeto, visando propor direçôes que contribuam tanto para a promoção de inclusão social, quanto ao desenvolvimento e crescimento do esporte de alto rendimento.

$\mathrm{O}$ objetivo geral deste trabalho foi investigar o esporte paralímpico e sua relação com a mídia. $\mathrm{O}$ objetivo específico foi descrever características da relação entre a mídia e o crescimento esportivo e comercial do movimento paralímpico no Brasil, com base em dados provenientes da literatura e de discursos de agentes atuantes no CPB.

\section{Categorias metodológicas da obra de Pierre Bourdieu}

Pierre Bourdieu oferece um modelo de investigação sociológica baseado em disputas sociais entre diferentes grupos que competem por ganhos simbólicos em determinados campos da sociedade. Para tal, apresenta uma série de categorias metodológicas que permitem uma análise sistemática a respeito das configuraçōes sociais que exercem interferência sobre as formas de ação dos sujeitos. Neste trabalho, tais componentes serviram como base para a interpretação dos dados oriundos das entrevistas, de modo a estabelecer uma linha de reflexão teórica sobre as formas de relação entre os meios de comunicação e diferentes agentes sociais atuantes no movimento 
paralímpico. As categorias utilizadas para tal análise são apresentadas nesta seção.

A Teoria dos Campos, elaborada por Pierre Bourdieu, serve como arcabouço científico para intervenções ligadas às relaçôes entre sujeitos que concorrem pelo poder e acesso a bens de disputa em determinados setores da sociedade. Organiza as análises a respeito de suas ações, posicionamentos e inter-relações, e se configura como uma ferramenta metodológica que auxilia em processos de apropriação de conhecimento frente a certos objetos, como o esporte, por exemplo.

A obra de Bourdieu se apoia no jogo de dominação existente em todas as áreas da sociedade. Tal ocorrência se dá devido à distribuição desigual de bens e ao acesso diferenciado a eles, de acordo com a posição que cada agente ocupa em seu espaço social. Essa diferenciação se dá a partir da consideração de que existem campos sociais de disputas, ou seja, espaços sociais de posiçóes em que os sujeitos buscam reconhecimento através da posse de formas de capital simbólico, específico desse ambiente.

Um campo social se conforma para esse autor através da definição dos objetos de disputas e dos interesses específicos desse espaço, que só são compreendidos por quem faz parte dele ${ }^{13}$. No campo, os agentes disputam o direito da violência simbólica, ou seja, o poder de orientar a conservação ou mudanças da estrutura de distribuição de capital, com base no seu reconhecimento como sujeito com destaque social, relativo à sua posse de capitais ${ }^{14}$. Dessa forma, cada campo específico se faz relativamente autônomo, ou seja, embora sofra certas influências do meio social que o cerca, tem suas regras e história próprias. Tem-se como exemplo a existência do campo esportivo, no qual os sujeitos lutam pelo reconhecimento no esporte, poder econômico e político (capitais específicos desse espaço) dentro dos princípios e critérios criados por seus agentes ${ }^{12}$.

As diferentes espécies de capitais, como trunfos em um jogo, são os poderes que definem as probabilidades de ganho em um campo determinado. Cada campo ou subcampo (espaços que respeitam as normas do campo de que fazem parte, mas também apresentam certas particularidades dentro dele) tem uma espécie particular de capital. Segundo MARQues et al. ${ }^{11}$, o esporte paralímpico configura-se, metodologicamente, como um subcampo do campo do esporte.

Têm-se quatro formas essenciais de capital que norteiam as disputas e que se inter-relacionam: econômico (quantidade de dinheiro em posse do agente), social (referente ao círculo social e relações interpessoais), cultural (aprendizado e conhecimento formal - ligado, entre outras formas, à escola regular e transmissão doméstica de conhecimento) e simbólico (específico de cada campo, é determinado pelo que o "habitus" e costumes daquele espaço indicam como algo a ser valorizado. Por exemplo, no esporte, uma das formas de capital simbólico é o mérito esportivo de um atleta $)^{13}$.

Além disso, Pierre Bourdieu apresenta, com certa especificidade em relação a outros autores das ciências sociais, um conceito muito importante, a ideia de "habitus", que se coloca como uma estrutura estruturante, ou seja, que norteia as formas de ação dos sujeitos ("práxis"), mas que é estabelecido de acordo com as leis do campo e os caminhos específicos para a disputa e aquisição de capital ${ }^{14}$. Nessa estrutura, temse que as disputas ocorrem entre agentes posicionados em diferentes grupos sociais, que são determinadas pela quantidade ou tipo de capital que possuem. Cada grupo tem seu "habitus" próprio, que justifica suas ações e norteia as práticas dos agentes na busca por aquisição desses bens ${ }^{15}$. Ao adquirir certa quantia de capital que justifique reconhecimento social, o agente pode ser aceito em outra esfera desse campo, podendo até mudar de grupo, estando sujeito a um novo "habitus". O estilo de vida dos agentes, segundo BOURDIEU $^{14}$, deriva das disposições e possibilidades encontradas por ele em seu grupo, e suas escolhas possíveis proporcionadas por seu "habitus".

\section{Método}

Esta pesquisa enquadra-se sob uma abordagem qualitativa. Configura-se como um procedimento exploratório-descritivo que busca pontuar as informaçôes oriundas dos discursos e documentos, discutindo e analisando seus conteúdos evidentes e latentes. Para desenvolver uma abordagem sobre um campo ou subcampo específico, Pierre Bourdieu sugere alguns passos metodológicos a serem seguidos. Um primeiro seria analisar a posição que o referido campo ocupa em seu espaço social. Em seguida, traçar um mapa da estrutura objetiva das relaçôes ocupadas pelos agentes ou instituiçôes que competem de forma legítima pela autoridade específica no campo. Por fim, devem ser analisados os "habitus" dos agentes ${ }^{16-17}$. 
Os dois primeiros passos indicados por Bourdieu são abordados na introdução deste trabalho e retomados com a análise de literatura utilizada na discussão dos resultados. Quanto à investigação específica sobre os agentes, foi realizada coleta de informaçôes com dirigentes do Comitê Paralímpico Brasileiro (CPB).

Como sujeitos da investigação foram escolhidos quatro dirigentes do $\mathrm{CPB}$, sendo dois envolvidos em questôes técnicas e dois em âmbito administrativo. Os critérios para isso deram-se com base na proximidade de cada um com o tema proposto, na posição de administração, gerência e liderança frente ao movimento paralímpico brasileiro e pelo acesso privilegiado a informaçôes relevantes ao trabalho que tais posições lhes permitem.

São características destes sujeitos: Sujeito 1 (S1): Professor universitário. Atua junto ao $\mathrm{CPB}$ em processos de classificação de atletas. Pessoa não deficiente; Sujeito 2 (S2): Professor de Educação Física. Atua em função administrativa no CPB. Pessoa não deficiente; Sujeito 3 (S3): Ex-atleta. Campeão paralímpico. Atua em função administrativa no $\mathrm{CPB}$; Sujeito 4 (S4): Ex-atleta. Campeão paralímpico. Atua em função administrativa no CPB.

A coleta de dados se deu através de entrevistas semiestruturadas, aplicadas pessoalmente pelos pesquisadores, com uso de aparelho gravador de voz digital e transcrição das respostas. Como os sujeitos atuam em esferas diferentes da administração paralímpica, cada entrevista foi direcionada para o tema de especialidade de cada um deles. Neste trabalho são apresentados somente os dados relacionados à mídia, cabendo a outras oportunidades a divulgação de outras temáticas tratadas nesta coleta de dados com dirigentes paralímpicos.

As entrevistas basearam-se em questões abertas, permitindo que o sujeito se expressasse com certa liberdade e que novos assuntos surgissem de acordo com o andamento da investigação, ampliando o espectro de questôes do roteiro inicial ${ }^{18-19}$. A temática deste artigo foi tratada por dois blocos principais de perguntas: 1) Existe alguma colaboração da mídia em relação ao crescimento e melhoria do esporte paralímpico brasileiro? O que seria ideal?; 2) Como é a relação do $\mathrm{CPB}$ com a imprensa brasileira? Existe algum acordo formal de colaboração? Cabe destacar que alguns dados emergiram de outras questões que surgiram durante as entrevistas.
Quanto aos procedimentos de organização de dados, foi utilizado o método "Discurso do Sujeito Coletivo”, baseado na construção de discursos que englobem posicionamentos comuns entre os entrevistado ${ }^{20}$. Tais discursos são denominados neste trabalho como DSC.

Tal procedimento se baseia em algumas figuras metodológicas que encadeadas e relacionadas distribuem e ordenam as informações. São elas: Expressões-chave (ECH) - trechos/partes literais do discurso que revelam a essência do mesmo; Ideias centrais (IC) - denota o tema central do discurso e indica os pontos que devem ser relevados na discussão do tema; Ancoragens (AC) - que apresentam os posicionamentos do sujeito que não são apresentados de forma explicita e as informações importantes sobre a ideia do entrevistado frente ao tema ${ }^{20}$.

O DSC se baseia em um discurso síntese redigido pelo pesquisador e composto pela soma das $\mathrm{ECH}$ de cada discurso individual que possui a mesma IC ou AC. Para a elaboração dos DSC deste trabalho, em um primeiro momento as $\mathrm{ECH}$ foram destacadas, facilitando a identificação dos dados. Depois, foram transportadas para Instrumentos de Análise do Discurso (IAD), no qual foram apontadas as IC e AC. Em um terceiro e último momento, com base em análise das $\mathrm{IC}$ e AC, as ECH foram agrupadas de modo a terem sentidos homogêneos, construindo assim, DSC diferentes ${ }^{20}$.

As entrevistas foram realizadas em locais previamente combinados com os sujeitos. Como os quatro indivíduos são membros do $\mathrm{CPB}$, esta pesquisa foi submetida e aprovada pela Comissão Científica da Academia Paralímpica Brasileira, que auxiliou na viabilização de contato e autorização a respeito dos locais de execução; e pelo Comitê de Ética em Pesquisa da Faculdade de Ciências Médicas da Universidade Estadual de Campinas, sob parecer $\mathrm{n}^{\circ}$ $356 / 2010$. Todos os sujeitos envolvidos assinaram o termo de consentimento livre e esclarecido previamente aprovado pelo Comitê de Ética.

A partir do material coletado, juntamente com informações relativas à literatura da área, a última etapa, de discussão dos dados, deu-se em diálogo, baseado em categorias próprias da obra de Pierre Bourdieu, entre aspectos ligados ao objeto de pesquisa, provenientes de estudo de campo e referencial teórico. 


\section{Resultados}

Os resultados são apresentados em forma textual, divididos em cinco DSC com temáticas diferentes, tendo suas sentenças baseadas nas ECH e seus títulos na IC e $\mathrm{AC}^{21}$. Entre parênteses são apontados os sujeitos que ofereceram ECH para a composição de cada DSC $^{22}$. Em texto recuado são apresentadas algumas ECH literais, de modo a destacar certos pontos de vista ou exemplificar alguns posicionamentos individuais.

\section{DSC1 (S2; S4): necessidade de maior divulgação midiática do esporte paralímpico}

O Brasil encontra-se com problemas para renovação e surgimento de novos talentos paralímpicos, visto que a divulgação desta forma de esporte ainda não é ideal, assim como a oferta de práticas. $\mathrm{O}$ esporte paralímpico ainda não é usual no dia-a-dia do brasileiro, o que dificulta atingir o interesse de novos atletas e da mídia, que pouco o explora (S2).

Há um incômodo com o fato do esporte paralímpico não ser amplamente divulgado, e por isso, pessoas leigas no assunto considerarem ser fácil chegar ao nível de alto rendimento esportivo. Esse tipo de ideia equivocada é resultado da falta de conhecimento do público em geral sobre toda a estrutura esportiva paralímpica no país. E a mídia pode ter um papel importante neste processo de divulgação (S2).

Porque não tem no dia-a-dia, não é como o futebol que todo mundo joga, que na educação física todo mundo joga handebol, basquete. Não tem paralímpico. Então o cara fala: "Pô, deve ser fácil de chegar porque não vejo ninguém jogando e os caras levam direto pra paralimpíada.". Daí o que falta, né, falta ter no diaa-dia em todos os locais, ter o esporte paralímpico na cabeça de todo mundo, é isso que falta. Não como esporte paralímpico do Comitê Paralímpico ou para a Paralímpiada, como prática de esporte como tem em qualquer lugar e todo mundo joga. Tem uma quadra em um prédio, tem um campinho de futebol na esquina em frente da casa. É isso, o paralímpico tem que ir lá pra quadra bater uma bolinha no basquete, tem que ir lá naquele campo jogar (S2).

O esporte paralímpico ainda não tem força suficiente para criar sozinho tal demanda de visibilidade no Brasil. Para a melhora neste quadro é preciso uma maior consolidação do esporte no país, visto seu surgimento recente e também ações coordenadas entre entidades de organização esportiva e meios de comunicação (S4).
... o que a gente faz é custear a operação de transmissão, então a gente compra o direito de transmissão, a gente operacionaliza a chegada do sinal aqui no Brasil e a gente leva os repórteres aqui da imprensa. Isso a gente ainda continua fazendo porque pra nós se não tiver visibilidade obviamente que a gente não vai conseguir o produto, é importante e a gente ainda não tem condição suficiente de por si só atrair a imprensa (S4). É preciso esforço para convencer o mercado e a mídia de que o esporte paralímpico é um bom produto (S2).

\section{DSC2 (S2; S4): processo de crescimento da visibilidade midiática do esporte paralímpico}

Embora ainda insatisfatória, a visibilidade do movimento paralímpico cresceu no Brasil após 2004, principalmente na mídia televisiva. Até então, apenas a mídia escrita se interessava (S2). Os Jogos Paralímpicos (JP) de 2004 e 2008 foram marcos quanto à importância dada pela mídia ao esporte paralímpico. A maior emissora do país exerceu uma grande cobertura, através de seu canal por assinatura específico para esporte (S4).

...tem surgido sim e a cada dia que a gente tem conseguido dar uma visibilidade que as empresas esperam, né, porque na verdade quando a empresa liga, vincula a marca dela a uma determinada modalidade ela está buscando visibilidade. Então nós tivemos agora, por exemplo, o mundial de natação transmitido ao vivo pela SportTV, as duas últimas paralimpíadas transmitidas pela TV. Eu acredito que a gente está evoluindo sim, ainda tem muito pra caminhar, pra evoluir, mas eu acredito que nós estamos conseguindo aí devagarinho consolidar o esporte paralímpico no Brasil (S4).

\section{DSC3 (S1; S2; S4): relação entre veículos de comunicação e entidades de organização do esporte paralímpico}

A relação entre $\mathrm{CPB}$ e veículos midiáticos, pautada na colaboração mútua e na organização profissionalizada do primeiro, permite trabalhos coordenados que potencializam a ação midiática do movimento paralímpico, ainda pouco aproveitada em muitos casos (S2; S4).

... o nosso relacionamento é muito bom, a gente tem um bom planejamento, não tem crises políticas, a gente não tem nada que arranhe o movimento paralímpico. Ele é muito novo, né, um movimento muito novo, de 20 anos, 15 anos na verdade que 
existe o Comitê Paralímpico, mas o movimento é um pouco mais de 20 anos. Então não tem, assim, crises políticas ou escândalos que abalem, então a gente ainda é bem visto pela mídia e a gente trabalha pra que essa visão não mude (S2).

Além da boa imagem administrativa do movimento paralímpico, existe ainda um significativo investimento, por parte do $\mathrm{CPB}$, na divulgação do esporte por meio de diferentes canais midiáticos, principalmente pela televisão (S2; S4).

É difícil hoje uma TV ter o interesse de comprar o direito de transmissão dos Jogos Paralímpicos, então o Brasil compra, o Comitê Paralímpico compra o direito de imagem e transfere gratuitamente para todas as TVs. E em Pequim já teve todos os jornalistas, [...], mas noventa por cento dos jornalistas estavam lá cobrindo, a gente levou, pagou a passagem, pagou hospedagem e alimentação deles, e pra isso a gente não cobra que falem bem da gente (S2).

Do mesmo modo, outro fator que contribui para tal quadro é a relação de cooperação, sem nenhum tipo de tensão, entre CPB e IPC (Comitê Paralímpico Internacional) (S1).

\section{DSC4 (S2; S3; S4): conteúdo da cobertura midiática: deficiência "versus" feitos atléticos}

Existem dois tipos principais de cobertura midiática sobre o esporte paralímpico: a de apelo social, ligada ao sensacionalismo e destaque para a necessidade de superação das adversidades da deficiência por parte dos atletas; e a que se apoia no rendimento atlético, com preocupação com resultados esportivos (S2; S3; S4). A cada dia a segunda forma tem crescido, mas ainda não chegou ao ponto ideal (S2; S4).

Tem as duas coisas. Tem a cobertura pelo lado social, ainda com um pouco de sensacionalismo, mas já tem aquela cobertura que visa exatamente cobrir uma modalidade de alto-rendimento. Se você acompanhar, por exemplo, as matérias que fecharam o Jornal $\mathrm{Na}$ cional durante a semana inteira do mundial de natação você vai perceber que as matérias ali elas já foram, realmente, como qualquer modalidade esportiva. $\mathrm{Ob}$ viamente citando exemplos, porque quando ela fala do atletismo, quando ela fala do futebol, de alguém que sai de uma condição adversa pra ser campeão de um resultado expressivo ela também o faz (S4).

Existe certo incômodo em relação à notícia sensacionalista com maior destaque à deficiência, pois ela coloca a pessoa em uma posição de inferioridade. Por outro lado, o destaque aos feitos atléticos pode transmitir a ideia de que as pessoas com deficiência têm importância e destaque na sociedade (S4). É preciso mostrar que as pessoas com deficiência são capazes de se auto-gerenciar e atuar como profissionais. $\mathrm{O}$ esporte teria esta capacidade (S3).

...fazem com que a gente agora já tenha na televisão uma representação que a gente gostaria de assumir pra nós, por exemplo, “Olha lá, é o nosso atleta.”, e antigamente as pessoas não faziam isso até porque o cara é deficiente e vai dizer "Poxa, eu vou atrelar o meu desejo a um produto com defeito?”, e hoje já fala "Pô, o Clodoaldo, o nosso atleta da natação". Tem pessoas que não têm deficiência e assumem ele como nosso atleta (S3).

Esse posicionamento ganhou força a partir de 1981, devido ao destaque dado pela ONU à necessidade de programas de inclusão social de pessoas com deficiência em escala mundial. Existe uma luta por inserção da pessoa com deficiência na sociedade, visto que todos cuidam dos idosos, pois as pessoas querem ficar velhas. Mas não há atenção com as pessoas com deficiência, pois ninguém quer ser uma (S3). Uma maior cobertura do esporte paralímpico, principalmente se associada a um maior destaque ao desempenho esportivo sobre o sensacionalismo referente à deficiência, poderia contribuir para esta afirmação e reposicionamento social, além de expandir possibilidades comerciais (S2; S3; S4).

\section{DSC5 (S2): diferenciações entre deficiências por parte da mídia}

Existe uma preferência por parte da mídia internacional, principalmente por meio da televisão, por divulgar modalidades em que os corpos dos atletas são pouco comprometidos em relação à deficiência, por exemplo, as modalidades que utilizam cadeira de rodas. Embora não haja essa tendência no Brasil, ela é um problema, pois como o país não tem predominância de atletas que utilizam cadeira de rodas, torna-se necessária uma transformação neste sentido, visando maior espaço aos brasileiros nos veículos de comunicação internacional (S2).

É claro que você, quando você vê na TV e quando você assiste pela primeira vez é muito mais interessante você ver um cadeirante, você ver, se você pegar um cego olhando você não vê a deficiência aparente, então no esporte paralímpico cadeirante vai chamar muito mais a atenção. O basquete pra cadeira de rodas hoje é sem dúvida o esporte mais bonito que tem se você levar em consideração o choque, a cadeira, aquele movimento, o basquete, o rugby, o próprio 
atletismo em cadeira de rodas. Isso é muito bonito, então isso chama a atenção, por isso que a tendência é investir nisso, isso chama a atenção porque na televisão é bonito, essa é a minha visão (S2).

\section{Discussão}

A discussão referente aos resultados deste estudo está dividida de acordo com os mesmos DSC oriundos das falas dos entrevistados e reflexões baseadas em dados da literatura da área e categorias metodológicas da obra de Pierre Bourdieu.

\section{DSC1: necessidade de maior divulgação midiática do esporte paralímpico}

Os discursos dos entrevistados sinalizam que há uma tendência e interesse pela abertura do subcampo do esporte paralímpico no Brasil para entrada de novos atletas. Porém, devido à pequena divulgação, por vezes existe, por parte do público em geral, a equivocada interpretação de que competições paralímpicas não exprimem um espaço de alto rendimento.

Existe no esporte paralímpico um "habitus" esportivo, ligado aos regimes de preparação, treinamento e competição, assim como no esporte olímpico ${ }^{2,6}$. Porém, como aponta BouRdieu ${ }^{14}$, as regras e os valores simbólicos do campo ou subcampo são compreendidos por quem faz parte dele e age de acordo com um dos "habitus" próprios de cada espaço social. Assim, o desconhecimento por parte do grande público, sobre as formas de organização do movimento paralímpico, não permite que estas pessoas percebam as formas de ação e pertinência deste subcampo, assim como as dificuldades próprias da trajetória do atleta para alcançar um nível de excelência esportiva.

Os entrevistados destacam que o esporte paralímpico no Brasil ainda não é capaz de criar sozinho um interesse suficiente no público que incentive um aumento de seu espaço na mídia. No mesmo sentido, BRITTAIN $^{2}$ coloca que os JP são a única oportunidade de um mínimo contato de muitas nações com o esporte adaptado. Outros estudos ${ }^{23-27}$ apontam isso como uma tendência mundial. Deste modo, a pequena atenção dada pela mídia ao movimento paralímpico configura-se como um problema para a renovação, crescimento e comercialização desta forma de esporte.

BOURDIEU ${ }^{9}$ destaca que um evento recorrente nos meios de comunicação é o destaque às notícias que vendem, ou seja, a importância e espaço destinado aos diversos conteúdos midiáticos não dependem apenas da sua pertinência ou importância, mas principalmente de sua capacidade de atrair a atenção de consumidores da notícia. Logo, expõe-se um quadro de necessidade de criação deste interesse por parte dos espectadores.

Uma das formas utilizadas por alguns autores para dimensionar o pequeno espaço destinado ao esporte paralímpico nos meios de comunicação se dá em comparações com o esporte olímpico. GONÇALVES et al. ${ }^{28}$ apontam que a mídia oferece um papel secundário aos atletas paralímpicos em relação aos olímpicos. Por exemplo, enquanto a cobertura midiática dos Jogos Olímpicos (JO) no Brasil de 2004 foi muito extensa, a atenção dada aos JP se restringia a notas na televisão aberta e transmissão em emissoras de televisão por assinatura ${ }^{29}$. Durante os JO e JP de 2008 foram publicados na mídia on-line 113 notícias referentes a atletas brasileiros e portugueses. Do total, $73 \%$ sobre esportistas olímpicos e $27 \%$ paralímpicos ${ }^{30}$.

Tal quadro de pouca divulgação não é exclusividade do Brasil. Percebe-se relatos de autores que denunciam a necessidade de maior divulgação do esporte paralímpico em outros países. Tem-se, por exemplo, relatos sobre Portugal e Estados Unidos.

Em Portugal, apesar da evolução do esporte paralímpico, principalmente em relação ao crescimento de situações de profissionalismo, as competiçôes para pessoas com deficiência apresentam baixa presença de público, sem a devida divulgação por parte dos meios de comunicação. Praticamente não existe um trabalho para a criação de ídolos esportivos e comercialização de seus nomes e imagem. Mesmo durante a realização dos JP, são divulgados apenas resultados e quadro de medalhas, realizando ainda uma comparação entre atletas olímpicos e paralím$\operatorname{picos}^{26}$. Esta comparação, referente ao número de medalhas, embora seja frequente e tenha ajudado a divulgar o esporte paralímpico ${ }^{11}$, se configura como um equívoco, pois desconsidera diferentes condiçōes de prática e disputa. Por exemplo, tem-se o número de medalhas oferecidas entre os Jogos de 2012 na natação - 102 nos JO e 444 nos JP ${ }^{31-32}$.

Segundo Hardin e Hardin ${ }^{33}$, nos Estados Unidos a cobertura midiática dos JP é mínima em comparação aos JO. Para eles, é virtualmente não existente. Como versam os mesmos autores, muitos jornalistas norte-americanos não veem o esporte 
adaptado como válido ou legítimo. No mesmo país, NIXON ${ }^{34}$ destaca que os JP de 2004 foram transmitidos aproximadamente dois meses após seu fim, posteriormente à cobertura estendida dos JO. Essa apresentação consistiu de duas horas de reprises sobre os 11 dias de competiçôes.

Além de prejuízos ligados à dificuldade de aproximação e surgimento de novos atletas paralímpicos, a pequena divulgação ainda ajuda na criação de um círculo vicioso, que não contribui para o aumento do interesse de empresas em investir no movimento paralímpico como estratégia de "marketing", visto que este ainda não conta com uma grande massa de espectadores. Ao mesmo tempo, sem tais investimentos, a divulgação por parte dos meios de comunicação diminui mais ainda, criando certa dependência de verbas públicas para a manutenção de atletas e equipes.

O interesse comercial no esporte se pauta pela proximidade dele com espectadores que se tornam clientes consumidores e o desejo de empresas se aproximarem dessas pessoas para vender seus produtos $^{6}$, neste sentido, a mídia pode ajudar na busca por patrocínios ${ }^{1}$ ou até gerar receita a partir de direitos de imagem, por exemplo.

Este é o caso do IPC, que não se sustenta com verbas estatais, mas sua arrecadação depende, em grande parte, dos direitos de imagem ${ }^{35}$ : direitos de imagem dos JP (60\% da arrecadação); Concessões e doaçôes (20\%); Patrocínios e apoios (17\%); Outras fontes (3\%).

Visto que em alguns países, incluindo o Brasil, o movimento paralímpico ainda é sustentado, principalmente, por financiamentos governamentais ou de empresas controladas pelo Estado ${ }^{11}$, é preciso que o movimento paralímpico torne-se mais atrativo comercialmente, aproximando-se dos veículos de comunicação.

Para isso, os agentes envolvidos neste subcampo devem se questionar sobre que fatores podem atrair leigos e consumidores para o esporte. Por exemplo, pode-se citar algumas atitudes do IPC, com o objetivo de divulgar os Jogos, que promove algumas alterações em regras e formas de competição, como na classificação de atletas por graus de comprometimento decorrente da deficiência, com a ideia de diminuição de classes de disputa ${ }^{36}$.

Outra possibilidade é investir na divulgação de feitos atléticos e a criação de ídolos esportivos, esta que segundo $\mathrm{PRONI}^{8}$, é uma estratégia bastante utilizada pela mídia esportiva em geral. Porém, de acordo com as falas dos entrevistados, poderia ser melhor explorada no esporte paralímpico, visto que o mérito esportivo, evidenciado pelos resultados e feitos dentro da disputa, configura o principal componente do capital simbólico do campo esportivo ${ }^{12}$, e assim gera e sustenta a idolatria aos atletas e atrai interesse ao espetáculo.

\section{DSC2: processo de crescimento da visibilidade midiática do esporte paralímpico}

Conforme apontaram os entrevistados, o esporte paralímpico no Brasil tem crescido em divulgação pelos meios de comunicação, principalmente após os JP de 2004. Percebe-se na literatura o mesmo discurso, corroborando com a posição dos sujeitos desta pesquisa. Para Figueiredo e Novais ${ }^{29}$, os JP de 2004 foram um marco na relação do movimento paralímpico com a mídia brasileira. Foi o ponto do início da transformação em espetáculo.

Tem-se como exemplo deste crescimento o dado de que o Brasil foi o país que mais horas transmitiu dos JP de 2004 (168 h), seguido pela Espanha (125 h) ${ }^{29}$. Porém, os entrevistados apontaram que tal crescimento não é satisfatório. Tal postura pode ser também encontrada na literatura. FLORENCE ${ }^{37}$, em estudo com 18 medalhistas brasileiros nos JP de 2004, descreve que eles alegam que a mídia só cobre os grandes eventos paralímpicos e destaca apenas as medalhas de ouro.

Nota-se que existe um movimento de aumento do espaço midiático dado ao esporte paralímpico no Brasil, porém, ainda centralizado em apenas grandes eventos e de forma pontual e não periódica.

Fora do Brasil pode-se perceber também certo processo de crescimento do espaço dado ao esporte paralímpico na mídia. Por exemplo, MACDONALD ${ }^{38}$ descreve que nos JP de 1996 atuaram 1600 jornalistas credenciados. Em 2000, foram 2400, e em 2008, 3100 representantes da imprensa internacional.

O esporte paralímpico disputa espaço nos meios de comunicação com outros produtos, como o esporte olímpico e diversas modalidades esportivas. Percebe-se que há inúmeras estratégias de maior inserção como produto midiático, como mudança da regra de classes de disputas ${ }^{36}$, privilégio a certos tipos de deficiências específicas ${ }^{24,26}$ e uso de sensacionalismo frente à deficiência².

Esse processo pode ser explicado como a luta descrita por Bourdieu, do "novo" contra o "velho", ou seja, do agente que tenta entrar na disputa por capital simbólico em um campo ou subcampo em que outros já estão estabelecidos, exercendo certa violência simbólica ${ }^{13-14}$. Assim, o esporte paralímpico, que busca maior espaço em relação a outros produtos esportivos, precisa assumir as regras do campo e 
incorporar um "habitus" que lhe confira maior reconhecimento simbólico, ou propor mudanças nas formas de distribuição do capital ${ }^{14}$. Ao que parece, com as estratégias apontadas, é que a primeira opção vem sendo a preferida dos dirigentes paralímpicos.

Outro exemplo da tentativa de adequação do movimento paralímpico às regras do jogo midiático é a existência de uma proposta para a facilitação de acesso a patrocinadores, que se baseia na integração total entre os JO e JP, o que poderia facilitar o crescimento comercial do segundo, porém, mudaria a identidade de $\operatorname{ambos}^{27}$.

\section{DSC3: relação entre veículos de comunicação e entidades de organização do esporte paralímpico}

Os entrevistados destacaram principalmente dois aspectos da relação entre veículos de comunicação e organizaçôes reguladoras do esporte paralímpico. $\mathrm{O}$ primeiro diz respeito à aproximação entre $\mathrm{CPB}$ e IPC ser harmoniosa e baseada na cooperação mútua (MARques et al. ${ }^{11}$ apontam que existem alguns membros do $\mathrm{CPB}$ com cargos administrativos importantes dentro de conselhos do IPC). O segundo, em relação ao momento de melhora das condições organizacionais e de profissionalismo do $\mathrm{CPB}$ nos últimos anos, uma relação de proximidade e credibilidade deste órgão com a mídia esportiva.

Principalmente em relação ao segundo aspecto, tem-se como exemplo o financiamento, por parte do $\mathrm{CPB}$, para viagens da imprensa a competiçôes importantes. Pode-se notar ações semelhantes de outros órgãos na tentativa de facilitar a divulgação do esporte paralímpico. Por exemplo o IPC, que criou uma plataforma própria na internet para transmissão dos JP (www.paralympicsport.com), mantida com verba de patrocinadores ${ }^{2}$. Tanto os entrevistados, quanto alguns dados da literatura, indicam que a necessidade de tais incentivos é cada vez menor, sendo que os meios de comunicação têm se interessado cada vez mais pelo esporte paralímpico.

Para os JP de 1996, 2000 e 2004, o CPB financiou a viagem da imprensa brasileira como forma de investimento na divulgação do esporte paralímpico. Já para os JP de 2008, o Brasil, que disputou 17 das 20 modalidades esportivas, teve, em âmbito mundial, a maior equipe de jornalismo e comunicação. A televisão fechada realizou transmissões diretas de jogos e provas individuais ${ }^{40}$.

Sob a ótica da Teoria dos Campos, de Pierre Bourdieu, tais ações expressam novamente a postura adotada pelas autoridades paralímpicas de assumirem-se como o "novo" que luta por espaço no campo midiático, de modo a buscar adaptar-se às regras do jogo e incorporar um "habitus" ligado ao comércio de práticas e produtos esportivos.

A principal mudança de "habitus" de uma instituição amadora que se torna profissional é o processo de reorganização para operar em empreendimentos comerciais, tanto em relação à sua forma de administração, quanto de preparação de atletas ${ }^{6}$. Como exemplo de ação ligada à busca pela melhoria da comercialização dos JP, tem-se a proposta de redução de classes de disputa através de um novo sistema de classificação que possibilite a ocorrência de menos campeões, evitando a inflação de medalhas, que desvaloriza a vitória, buscando uma compreensão e consumo facilitados por parte do público em relação aos Jogos. Em alguns casos, os atuais sistemas confundem o espectador, influenciando na capacidade de exploração de mídia e mercado do esporte ${ }^{24,36}$.

A busca por crescimento da perspectiva comercial do esporte paralímpico se dá, em certa parte, pela ação do IPC em aproximar-se do Comitê Olímpico Internacional (IOC), o que facilitou contatos e incorporou não só a imagem, como ganhos antes apenas vinculados aos JO.

O acordo entre IPC e IOC, realizado em 2003, referente a repasses de direitos de imagem do segundo para o primeiro, determina que os direitos de transmissão e responsabilidade de "marketing" dos JP de 2008, 2010 e 2012 foi do Comitê Organizador de ambos os Jogos, ligado a cada cidade-sede ${ }^{36}$.

Através de acordos como este, o IPC tem seus negócios financeiros facilitados, podendo investir no crescimento do esporte para pessoas com deficiência. Porém, a desvantagem é que ficam dificultadas ações de educação da população em relação à atividade motora adaptada, visto que as açôes de "marketing" de ambos os Jogos são praticamente as mesmas ${ }^{36}$.

\section{DSC4: conteúdo da cobertura midiática: deficiência versus feitos atléticos}

Com base no discurso dos entrevistados, fica latente certa tensão e disputa entre agentes do movimento paralímpico e meios de comunicação que, como indica BouRdieu', na busca por vender suas notícias, destacam o que lhes é interessante. Percebe-se que o capital simbólico valorizado pela mídia no campo do espetáculo esportivo diz respeito, entre outros fatores, à exaltação de feitos atléticos e ao culto ao corpo, respeitando um 
estereótipo estético próprio contemporâneo. Porém, tanto entrevistados, como a literatura, indicam que tais critérios não vêm sendo necessariamente aplicados ao esporte paralímpico.

Nesse caso, a mídia tem priorizado o sensacionalismo frente à deficiência em detrimento do destaque aos feitos esportivos dos atletas. Isso, que se por um lado, auxilia na quebra de estereótipos e paradigmas frente à pessoa com deficiência na sociedade, não contribui para a valorização do produto esporte, dificultando a atração do interesse de patrocinadores e divulgação para captação de novos talentos. Desse modo, existe certa premiação simbólica à deficiência do atleta, em detrimento de sua funcionalidade esportiva.

Como apontam os entrevistados e a literatura consultada, a perspectiva sensacionalista desagrada à comunidade paralímpica, que prefere ser referida em notícias pelos seus feitos atléticos e não por suas deficiências ${ }^{24,37}$. Porém, nesse processo, o caráter de alto rendimento e busca por bons resultados ainda não é destacado pela imprensa como foco principal nos JP ${ }^{6}$. Durante os JP de 1996, as coberturas de mídia de França e Alemanha agiram exatamente do modo criticado, com pouca ênfase aos feitos atléticos, sendo que o desempenho esportivo dos competidores era destacado apenas através da divulgação do quadro de medalhas. Isso talvez tenha ocorrido devido ao pouco espaço destinado a essa forma de manifestação esportiva nos meios de comunicação. Quando houve especificidade, esta não foi ligada a aspectos técnicos, mas sim a escândalos, problemas e questóes tecnológicas ${ }^{34}$. Pereira et al. ${ }^{26}$ apontam o mesmo quadro ligado à mídia portuguesa.

Têm-se neste espaço dois grupos sociais em disputa, a mídia e o Movimento Paralímpico. A primeira exerce a violência simbólica de determinar quando e como é transmitido o esporte, visto que o segundo depende de sua divulgação para captar recursos e material humano para sua sobrevivência, e por isso busca alternativas e resignifica seu "habitus" em um sentido de convencer os meios de comunicação sobre seu valor simbólico e comercial.

Ao mesmo tempo em que há uma disputa pelo tipo de transmissão predominante - sensacionalista, com foco na deficiência; ou esportiva, com foco nos feitos atléticos - há uma tentativa de aproximação por parte do segundo grupo em busca por melhores espaços de divulgação, espetacularização e lucros. Sendo estas, formas de capital em disputa muito importantes nesta relação. Tal tentativa de ganhos simbólicos no espaço midiático se dá por transformaçôes dos "habitus" de alguns agentes no subcampo, como classificadores, técnicos, atletas, administradores, para uma perspectiva mais ligada ao crescimento do profissionalismo e facilitação de comercialização do movimento paralímpico.

Isso configura, frente à caracterização dos campos sociais de Bourdieu ${ }^{14}$, a autonomia relativa deste subcampo frente às imposições de órgãos próprios da sociedade como um todo, como a mídia e o comércio específico do esporte. Onde o esporte paralímpico é apenas mais um conteúdo e possibilidade de produto, dentre tantos outros.

Nota-se nesta situação, um conflito onde, por um lado, posicionam-se os agentes do movimento paralímpico, que querem ser tratados como atletas de alto rendimento e terem seus feitos esportivos valorizados. E por outro a mídia, que vende a notícia por meio das mensagens ligadas à superação de adversidades ${ }^{41}$, visto que tal discurso ligado ao "exótico humano", no qual o atleta com deficiência é tratado como coitado, tem gerado maiores índices de audiência, reforçando estereótipos preconceituosos ${ }^{30}$.

Alguns autores defendem que a publicidade sobre os feitos esportivos do atleta com deficiência pode ajudar a remover barreiras sociais sobre estas pessoas ${ }^{42-43}$, além de contribuir para a criação de uma massa consumidora do esporte ${ }^{39}$. Porém, a tendência dos meios de comunicação em transmitir o estereótipo de "superatleta com deficiência”, no qual destaca as façanhas ligadas à superação das dificuldades impostas pela deficiência na vida diária, aumenta o foco sobre a deficiência e diminui a atenção sobre suas potencialidades ${ }^{2}$, reforçando estigmas e posturas preconceituosas ${ }^{30,43}$.

Nesse sentido, a mídia muitas vezes ressalta os atletas paralímpicos como bravos, corajosos, quase super-heróis que superam suas adversidades, agregando valores externos à esfera esportiva e apelando ao sentimento de compaixão dos espectadores ${ }^{29-30}$. Porém, além disso, poderia priorizar momentos em que estes sujeitos possam se expressar apenas como atletas, passando a serem admirados pelo que podem fazer esportivamente ${ }^{27}$, afinal de contas são, em essência, atletas como qualquer outros.

Assim como no esporte convencional, no paradesporto também é vitorioso somente o mais veloz, mais forte, mais ágil. A diferença é que velocidade, força e agilidade aparecem entre próteses, vendas nos olhos e outras adaptações estruturais ${ }^{28}$ (p.161).

\section{DSC5: diferenciações entre deficiências por parte da mídia}

Tanto o discurso do entrevistado S2, quanto alguns registros na literatura ${ }^{24,26,44}$ apontam que existe, 
por parte da mídia, uma preferência por divulgação de modalidades disputadas por atletas que utilizam cadeira de rodas.

Um dos motivos de certo desinteresse da mídia por algumas modalidades paralímpicas é a presença de corpos desvinculados dos padrôes de beleza da sociedade contemporânea. As modalidades em cadeira de rodas são mais valorizadas do que outras, pois não só representam uma imagem estereotipada da pessoa com deficiência, como possibilitam atletas com corpos mais próximos dos padrões sociais ${ }^{6}$, o que atende aos interesses comerciais dos meios de comunicação.

Outro exemplo disso é o fato de que atletas com paralisia cerebral não foram tratados em nenhum artigo sobre os JP de 1996, tanto na imprensa alemã, quanto francesa. Nesses casos, a prioridade sempre foi dada aos atletas que utilizam cadeira de $\operatorname{rodas}^{24}$. $\mathrm{Na}$ imprensa portuguesa, quanto menos visível a deficiência, maior a probabilidade de a notícia ser ilustrada com uma fotografia do atleta ${ }^{26}$. Tais informaçóes levam à percepção de que, de modo geral, a pessoa com deficiência não é valorizada do ponto de vista estético ${ }^{6}$.

$\mathrm{Na}$ sociedade contemporânea ainda existe certa resistência em associar os atletas com deficiência a marcas e produtos. Isso ocorre, entre outros fatores, devido à visão preconceituosa sobre sujeitos diferentes, sustentada por três aspectos principais: 1) incômodo estético que impede que a pessoa com deficiência seja vista como bela frente aos padróes sociais estabelecidos; 2) Falta de identificação com as pessoas com deficiência por parte dos consumidores; 3) Dificuldade de apreciar uma imagem tida como frágil aos valores de superioridade e vitória agregados à competição esportiva ${ }^{45}$.

O "marketing" esportivo valoriza o "capital físico" (forma de capital simbólico atrelado ao campo da divulgação esportiva) do ponto de vista do rendimento atlético e da estética. Nesse sentido, existe o interesse, por parte do IPC, pela redução de classes de disputa entre deficiências, o que, talvez de modo negativo, privilegiaria sujeitos menos comprometidos e padrões corporais mais próximos de atletas não deficientes ${ }^{6}$. Percebe-se, neste posicionamento, que a busca pela valorização do movimento paralímpico como produto de mercado acaba por instaurar uma lógica peculiar de disputa por capital simbólico no subcampo.

Uma eventual redução de classes de disputa seria um modo de reorganizar os processos e critérios de valorização de feitos esportivos e possibilidades de vitória dos atletas, o que redistribui as possibilidades de ganhos e recompensas externas ao esporte, sejam elas econômicas ou sociais. Tal aproximação é uma aceitação, por parte do esporte, da eventual necessidade de adequar-se às tendências mercadológicas da notícia, ou seja, de expor suas características de forma mais apropriada para vender notícia sobre seu produto, submetendo-se à violência simbólica dos meios de comunicação 9 .

Porém, é necessário cuidado nas mudanças e adaptaçôes mercadológicas para que os eventos não percam o caráter de empoderamento e aceitação de diferentes atletas com deficiência, inclusive os mais comprometidos ${ }^{24}$. Essa característica deve ser mantida, pois é a principal identidade dos JP e o expoente do movimento paralímpico. Sem a exposição das diferenças e capacidades específicas, o esporte adaptado iguala-se demais ao convencional, perdendo sua riqueza e valor.

Neste sentido, ScHANTZ e GILBERT ${ }^{24}$ destacam que há possiblidades de investimento nesta característica peculiar dos JP. Segundo os autores, diferentemente da cobertura olímpica, onde comprometimentos físicos são problemáticos, na paralímpica colocam-se como uma possibilidade de apresentação, pouco explorada, de novas perspectivas de ação e patrocínio.

É com este cenário que S2 parece se preocupar. Além das dificuldades com oferta de modalidades com cadeira de rodas no Brasil, a maior valorização de práticas não tão acessíveis no país pode tanto diminuir a importância e oportunidades em modalidades mais baratas, assim como oferecer menores chances de ganhos financeiros a atletas que não tenham acesso a materiais como cadeira de rodas, prejudicando, em alguns casos, processos de empoderamento e inclusão social.

Com base nas informações apresentadas e discutidas, pode-se sugerir que a exploração do movimento paralímpico por parte da mídia brasileira é algo a ser melhorado. $\mathrm{O}$ campo esportivo como um todo (espaço social em que o esporte paralímpico faz parte) legitima um capital simbólico muito próprio atualmente, ligado à valorização do mérito atlético e da capacidade comercial. Segundo Coakley ${ }^{7}$, além de preocuparem-se com bons resultados em competições, os agentes envolvidos precisam estar atentos à sua imagem midiática, pois a exposição positiva pode significar maiores ganhos financeiros e melhores condições de preparação, treinamento e obtenção de resultados esportivos mais expressivos.

Os dados apresentados permitem sugerir que o movimento paralímpico ainda não possui um capital simbólico que o legitime comercialmente do mesmo modo que o esporte olímpico, embora se encontre 
em processo de transformação de algumas de suas práticas sinalizando uma tentativa de se tornar mais adequado ao mercado esportivo.

É possível perceber, com base nos discursos dos sujeitos, manifestações dos veículos de comunicação que tratam o esporte paralímpico não como um fenômeno exatamente esportivo, mas sim, como um espaço de exposição e apresentação de pessoas que buscam se afirmar socialmente. Como tentativa de destinar maior valorização aos feitos atléticos, o movimento paralímpico opta por adequar-se a certas regras do campo midiático, como tornar suas disputas mais simples para o grande público, por exemplo. Ao mesmo tempo, busca expor a similaridade entre o sentido da vitória e da derrota, do sucesso e do fracasso esportivos entre os universos olímpico e paralímpico.

Atualmente, o público consumidor de esporte tem poucas oportunidades de melhor conhecer o movimento paralímpico. A mídia em geral não investe neste produto de modo incisivo e isso acaba limitando as possibilidades de expansão desta forma de esporte. Para buscar maior espaço comercial, pode ser interessante que o movimento paralímpico continue seu processo de busca por aumento da profissionalização e se adeque a direções propostas pela mídia. Talvez com isso, venha a melhorar a exposição de sua vertente esportiva de alto rendimento, mostrando sua capacidade de criar ídolos, produzir emoções prazerosas e atrair interesse de espectadores.

Neste processo, transformações em regras, formatos de competições e modos de organização de eventos podem ser importantes, desde que não agridam certo equilíbrio entre empoderamento e inclusão social de pessoas com deficiência e comercialização do esporte.

Concomitante a tais modificações, a deficiência não poderia ser tratada como impedimento para uma participação social plena, mas sim, uma característica dos atletas, que querem ser vistos como tal e valorizados por suas capacidades. $\mathrm{O}$ sensacionalismo sobre a deficiência, ligado à superação de dificuldades, pode, em um primeiro momento, expor certa vertente espetacular e agregar audiência, porém, não tem consolidado o movimento paralímpico como um produto esportivo com potencial duradouro de mercado. A mudança quanto às relações entre mídia e o esporte paralímpico podem ser revistas e transformadas, principalmente valorizando os feitos atléticos e o potencial gerador de emoção e comércio que os atletas e as competições podem oferecer.

\begin{abstract}
Media and Brazilian paralympic movement: relationships under Brazilian Paralympic Commitee manager's perception

The goal of this study was to investigate the relationship between media and disclosure and commercialization of Brazilian Paralympic Movement. The research methodology was based on: semistructured interviews with managers of the Brazilian Paralympic Committee about management processes of the paralympic movement and relationship with the media; Data from interviews were analyzed using the Discourse Collective Subject method and reflections based on Pierre Bourdieu's categories. Results: the exploitation of the paralympic movement by the Brazilian media is something that can be improved; Paralympic sport does not have a symbolic capital that legitimizes commercially, although it has developed in this regard; To reach better commercial relevance, it may be interesting that the Paralympic movement continues its search process by increasing professionalization and fits the directions proposed by the media. Due to such approach, the exposure of your slope high performance sport might be improved, showing its ability to create idols, produce pleasurable emotions and attract interest of consumers.
\end{abstract}

KeY WORDS: Sport; Paralympic; Media; Adapted physical activity; Pierre Bourdieu. 


\section{Referências}

1. Howe PD. The cultural politics of the paralympic movement: through an anthropological lens. New York: Routledge; 2008

2. Brittain I. The paralympic games explained. New York: Routledge; 2010.

3. Bailey S. Athlete first: a history of the paralympic movement. West Sussex: John Wiley \& Sons; 2008.

4. Araújo PF. Desporto adaptado no Brasil: origem, institucionalização e atualidade. Brasília: Ministério da Educação e do Desporto/INDESP; 1998.

5. Potência inesperada: uma aplicação eficiente de recursos explica os bons resultados do Brasil nos jogos de Pequim. Rev Época. 2008;539.

6. Howe PD. Sport, professionalism and pain: ethnographies os injkury and risk. New York: Routledge; 2004.

7. Coakley J. Sports in society: issues and controversies. 10th ed. New York: McGraw-Hill; 2008.

8. Proni MW. A reinvenção dos Jogos Olímpicos: um projeto de marketing. Esporte Soc. 2008;3. Disponível em: http:// www.uff.br/esportesociedade/pdf/es904.pdf.

9. Bourdieu P. Sobre a televisão. Rio de Janeiro: Jorge Tahar; 1997.

10. Brasil, Presidência da República, Casa Civil, Subchefia para assuntos jurídicos. Lei no 9.615. 2003. [citado 1 maio 2013]. Disponível em: http://www.planalto.gov.br/ccivil_03/leis/19615consol.htm.

11. Marques RFR, Duarte E, Gutierrez GL, Almeida JJG, Miranda TJ. Esporte olímpico e paraolímpico: coincidências, divergências e especificidades numa perspectiva contemporânea. Rev Bras Educ Fís Esporte. 2009;23:365-77.

12. Bourdieu P. Coisas ditas. São Paulo: Brasiliense; 1990.

13. Bourdieu P. O poder simbólico. Rio de Janeiro: Bertrand Brasil; 1989.

14. Bourdieu, P. Questôes de sociologia. Rio de Janeiro: Marco Zero; 1983.

15. Bourdieu P. Razões práticas: sobre a teoria da ação. Campinas: Papirus; 1996.

16. Bourdieu P, Chamboredon J-C, Passeron J-C. A profissão de sociólogo: preliminares epistemológicas. 3a ed. Vozes: Petrópolis; 2002.

17. Souza J, Marchi Junior W. Por uma sociologia reflexiva do esporte: considerações teórico-metodológicas a partir da obra de Pierre Bourdieu. Movimento. 2010;16:293-315.

18. Minayo MCS. O desafio do conhecimento: pesquisa qualitativa em saúde. 9a ed. São Paulo: Hucitec; 2006.

19. Charmaz K. A construção da teoria fundamentada: guia prático para análise qualitativa. 2a ed. Porto Alegre: Artmed; 2009.

20. Lefevre F, Lefevre AMC. Como fazer o discurso do sujeito coletivo passo a passo. In: Lefevre F, Lefevre AMC. O discurso do sujeito coletivo: um novo enfoque em pesquisa qualitativa (desdobramentos). 2a ed. Caxias do Sul: EDUCS; 2005, p.37-57.

21. Andrade AMBA, Bucher JSFN. A resiliência à luz do discurso do sujeito coletivo: uma contribuição ao programa de saúde da família. In: Lefevre F, Lefevre AMC. O discurso do sujeito coletivo: um novo enfoque em pesquisa qualitativa (desdobramentos). 2a ed. Caxias do Sul: EDUCS; 2005. p.217-32.

22. Mazza MMPR, Lefevre F. Cuidar em família: análise da representação social da relação do cuidador familiar com o idoso. Rev Bras Cresc Desenv Hum. 2005;15:1-10.

23. Davies RW, Ferrara MS. Sports medicine and athletes with disabilities. In: Depauw K, Gavron SJ. Disability and sport. Champaign: Human Kinetics; 1995. p.133-49.

24. Schantz OJ, Gilbert K. An ideal misconstructed: newspaper coverage of the Atlanta Paralympic games in France and Germany. Sociol Sport J. 2001;18:69-94.

25. Sainsbury T. Paralímpicos: pasado, presente y futuro: lección universitária olímpica. Barcelona: Centre d’Estudis Olimpics (UAB); 2004.

26. Pereira AL, Silva MO, Pereira O. O valor do atleta com deficiência: estudo centrado na análise de um periódico português. Rev Port Ciênc Desp. 2006;6:65-77.

27. Gold JR, Gold MM. Acess for all: the rise of the Paralympic Games. J R Soc Promot Health. 2007;127:133-41.

28. Gonçalves GC, Albino BS, Vaz ALF. O herói esportivo diferente: aspectos do discurso em mídia impressa sobre o Parapan-americano 2007. In: Pires GL, organizador. Observando o pan Rio/2007 na mídia. Florianópolis: Tribos da Ilha; 2009. p.149-67.

29. Figueiredo TH, Novais RA. Atletas com deficiências na mídia: a cobertura noticiosa dos jogos Paraolímpicos de Atlanta a Pequim nas imprensas portuguesa e brasileira. Anais do CONFIBERCOM. Jul-31 2011; São Paulo, BR; São Paulo: ECA-USP; 2011.

30. Novais RA, Figueiredo TH. A visão bipolar do pódio: olímpicos versus paraolímpicos na mídia on-line de Brasil e de Portugal. Logos 33. 2010;17:78-89. 
31. IOC. International Olympic Committee. Search for medalist. 2012. [citado 1 maio 2013]. Disponível em: http:// www.olympic.org/content/results-and-medalists/gamesandsportsummary/?sport=42422\&games=2012\%2f1\&event=.

32. IPC. International Paralympic Committee. Medal standings. 2012. [citado 1 maio 2013]. Disponível em: http:// www.paralympic.org/Athletes/Results.

33. Hardin M, Hardin B. Elite wheelchair athletes telate to sport media. In: Gilbert K, Schantz OJ, editors. The Paralympic Games: empowerment or side show? Maidenhead: Meyer \& Meyer; 2008. p.25-33.

34. Nixon HL II. Constructing diverse sports opportunities for people with disabilities. J Sport Soc Issues. 2007;31:417-33.

35. IPC. International Paralympic Committee. History and background os IPC and Paralympic Games. Vancouver: IPC; 2005. (Paralympic Games Workshop).

36. Howe PD, Jones C. Classification of disabled athletes: (dis) empowering the paralympic practice community. Adapt Phys Activ Q. 2006;23:29-46.

37. Florence RBP. Medalhistas de ouro nas paraolimpíadas de Atenas 2004: reflexões de suas trajetórias no desporto adaptado [tese]. São Paulo(SP): Universidade Estadual de Campinas, Faculdade de Educação Física; 2009.

38. MacDonald M. Media and the paralympic games. In: Gilbert K, Schantz OJ, editors. The Paralympic Games: empowerment or side show? Maidenhead: Meyer \& Meyer; 2008. p.68-78.

39. Marques RFR, Gutierrez GL, Almeida MA. Investigação sobre as configuraçōes sociais do subcampo do esporte paralímpico no Brasil: os processos de classificação de atletas. Rev Educ Fís/UEM. 2012;23:515-27.

40. Costa AM. Esporte adaptado no Brasil: evolução e perspectivas. III Congresso de Ciências do Desporto/II Simpósio Internacional de Ciências do Desporto; 2009; Campinas, BR. Campinas: Universidade Estadual de Campinas; 2009.

41. Howe PD. The tail is wagging the dog: body culture, classification and the paralympic movement. Etnography. 2008; 9:455-517.

42. Hardin M, Hardin B. Elite wheelchair athletes relate to sport media. In: Gilbert K, Schantz OJ, editors. The paralympic games: empowerment or side show? Maidenhead: Meyer \& Meyer; 2008. p.25-33.

43. Pappous A, Marcellini A, Leseleuc, E, et al. La representación midiática del deporte adaptado a la discapacidad em los médios de comunicación. Ágora Educ Fis Deporto. 2009;9:31-42.

44. Howe PD. Cyborg and supercrip: the paralympians technology and the (dis) empowerment of disabled athletes. Sociology. 2011;45:868-82.

45. Faria MD, Carvalho JLF. Uma análise semiótica do potencial mercadológico da imagem de atletas paraolímpicos. Rev Gestão Soc. 2010;4:657-86.

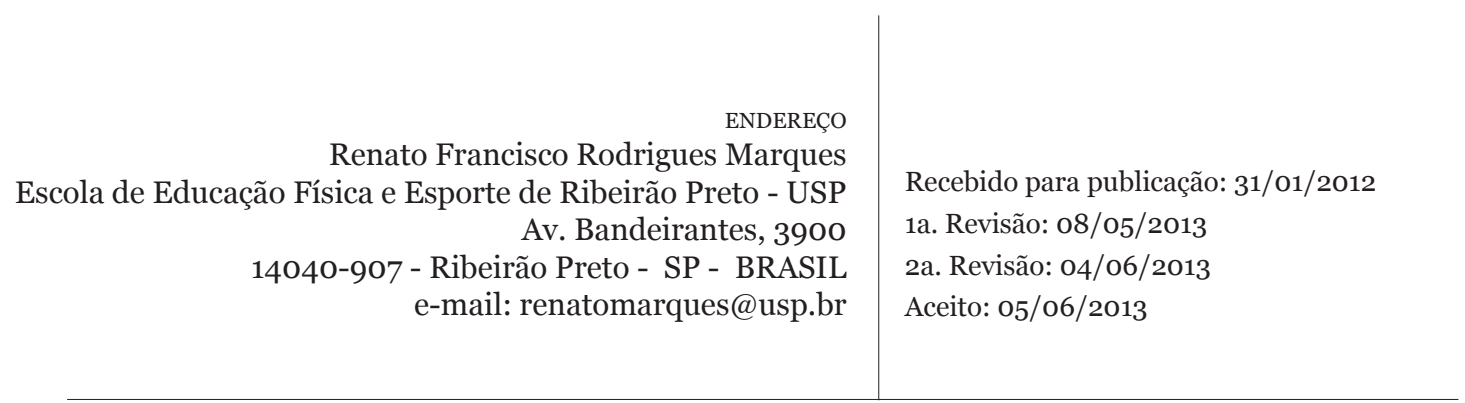

